\title{
COMPARISON OF ORAL HEALTH IN CHILDREN AGED 5-6 YEARS IN THE CZECH REPUBLIC AND YEMEN
}

\author{
Nabil Salah ${ }^{1,2}$ \\ ${ }^{1}$ Department of Health Promotion and Protection, Faculty of Medicine, Masaryk University, Brno, Czech Republic \\ ${ }^{2}$ Faculty of Dentistry, Thamar University, Thamar, Yemen
}

\section{SUMMARY}

Objective: Dental caries is the most widespread oral disease in the world, with multifactorial aetiology. It hinders not only the ability to eat good food, but also affects perfect speech and well-being. As the disease is almost completely preventable, and at its early stage well treatable, the prevalence of dental caries expresses the lack of public health literacy and skills in dental hygiene, and availability of adequate dental care. Children are especially vulnerable to dental caries, hence the WHO recommends regular monitoring of children's oral health and also appropriate controls for its continual improvement. We describe the part of the study targeted on dental health of Czech (CR) and Yemeni (YE) school children and its association with basic anthropometric markers of their nutrition.

Methods: Total of 190 children aged 5-6 years (100 from CR and 90 from YE, 111 males, 79 females $-22.5 \%$ of the wider study on 5-15 years old children) were involved (after obtaining informed consent from their parents). The sample is not representative. All dental examinations were performed in accordance with the WHO criteria by the same examiner. Each individual tooth, whether primary or permanent, was identified as intact, untreated decayed, extracted or filled. Also, dmft/DMFT indexes for individual children were calculated. Anthropometric measurements were performed by standardized methods and the body mass index (BMl-for-age) was calculated. For the statistical evaluation of differences, the program MedCalc Software Inc., Belgium, was used, especially t-test, Pearson's correlation (rho with 95\% confidence interval (Cl) and Spearmen's rank correlation coefficient; p-values less than 0.05 were considered significant.

Results: Dental caries prevalence and dmft scores (2.12-4.31) were found to be rather high among this age group of children, with no significant differences in relation to gender and country; only $30.0 \%$ or less of children were caries free. The decayed component was the major part of the $\mathrm{dmft}$ scores, and the evaluation of restorative index (ri\%) indicates a high percentage of untreated caries and a high treatment need. Especially in Yemeni children dental caries is wholly untreated (ri $0.0 \%$ ), but also in the CR the dental care is rather poor (ri 38-41\%). The levels of association(s) between oral health markers (dmft/DMFT) and BMI were inconsistent (both positive and negative), but without statistical significance.

Conclusions: The high prevalence of poor dental health in these groups of Czech and Yemeni children and low or even no treatment urge effort to include WHO recommendations for practice into the national health policies. Prevention and control of dental caries can be promoted not only by dentists, targeting children and the whole family and their dental habits and lifestyle, with the cooperation of schools, paediatricians, general practitioners and with gynaecologists targeting new and expectant mothers, to increase their knowledge and skills.

Key words: dental health, children aged 5 years, risk factors, prevention, Czech Republic, Yemen

Address for correspondence: Nabil Salah, Department of Health Promotion and Protection, Faculty of Medicine, Masaryk University, Kamenice 5, 62500 Brno, Czech Republic. E-mail: nabil@seznam.cz

https://doi.org/10.21101/cejph.a4893

\section{INTRODUCTION}

Dental caries (tooth decay) is one of the most prevalent chronic diseases of humans worldwide. People are susceptible to the disease throughout their lifetime. It is the primary cause of oral pain and tooth loss. Dental caries disturbs not only the ability to eat good food, but also hinders perfect speech and general wellbeing. Dental caries is the localised destruction of susceptible dental tissues by acid by-products, from bacterial fermentation of dietary carbohydrates. This process is initiated within the bacterial biofilm (dental plaque) on the tooth surface. It can potentially be prevented and reversed in its early stages (1).

Caries in the primary teeth of preschool children is commonly termed as Early Childhood Caries (ECC). It is a multifactorial disease, not only local for teeth, but it affects children's general health, growth patterns and quality of life. The treatment of the disease may be costly, complicated and time-consuming, and stressful for some patients (2).

Age is one of the contributing factors identified by various studies. The WHO considered the age of 5 years to be important and interesting in relation to caries in the primary dentition, which may exhibit changes in permanent dentition. Thus children 5-yearold are a target group for screening, as prevention for developing oral disease. (3).

In many developed countries, dental caries rates have improved among children in recent decades; nevertheless, the progress has recently ceased. Studies clearly show a discrepancy in distribution and severity of the oral disease, not only between countries but also between population in the same county. Even in the economic rich countries with modern health care, the polarization of oral health markers (decayed, missing and filled teeth - indexes dmft/DMFT) means that a small proportion of 
cohorts has poor oral health, while the rest remain virtually healthy (4).

As the dental caries is a multi-factorial disease, where majority of risk factors are preventable, it should be a priority for the public health policy to create and implement methods for prevention.

Many epidemiological and clinical studies were concerned about the risk factors for dental caries in deciduous teeth of children aged up to 6 years. The highest pro-cariogenic importance is shown as follows (5):

- Oral cariogenic bacterial microflora, such as lactobacilli and especially mutans streptococci acquired at an early age, with the contribution by maternal contamination (kissing, prefasting food, cleaning a dummy).

- Dietary factors (low magnesium and calcium intake), and namely high sugar consumption, especially between meals. The most cited Swedish study (6) described even in the middle of the 20th century, that sugars have an aetiological role in dental caries, as they are the nutritional substrates for cariogenic bacteria, which produce the enamel demineralization. The follow-up process to detectable caries depends on multiple factors, such as oral hygiene and fluoride supplementation (7). So, in developed countries, but not in economically transformed and developing countries, the role of sugar is not so strong as it was in the pre-fluoride era. Nevertheless, the control of sugar consumption is still an important part of caries prevention (8).

- Socioeconomic (family) factors: poverty, parental low basic educational level and/or (their) young age at the time of childbirth, (their) cohabitation is often associated with children's frequent use of sugar and sweets, as children watch TV for hours. Existing parental dental caries and inadequate oral hygiene significantly contributes to poor children's dental health (9).

- Inappropriate methods of infant feeding, namely prolonged breastfeeding and/or giving sweet drinks during the night (5).

- Inadequate salivary flow and composition (5).

- Insufficient fluoride exposure: fluoride acts as a catalyst for the diffusion of calcium and phosphate into the tooth and so surfaces composed of fluoridated hydroxyapatite and fluorapatite are much more resistant to acid attack (5).

- Ethnic minority groups, recent immigrants, children with the low birth weight history are associated with higher risk of dental caries in childhood, especially with ECC (1).

Risk classification should be periodically reviewed and updated, as the future progression or reversal of caries depend on a balance between demineralization and remineralization (1).

The hereditary non-preventable risk seems to be matrix metalloproteinases, which were confirmed to play an important role during the initial processes of enamel development and therefore may influence the caries prevalence, especially in associations with poor oral health habits (10).

We present part of the study, the aim of which was to evaluate and compare the dental health status of school children in the Czech Republic (CR) and Yemen (YE), and to assess the possible relationship of dental caries prevalence and body mass index (BMI). From the wider study including together 845 children aged 5-15 years, only the group of 5-6 year age category was chosen for this presentation ( $22.5 \%$ of the whole sample).

\section{MATERIALS AND METHODS}

Together 190 children (100 from CR and 90 from YE, 111 males, 79 females) were involved; the sample is non-representative, without any demographic randomization in $\mathrm{CZ}$ and some randomization in YE (town, village) as children were asked for the participation in the dental office or at school (after obtaining informed consent from the parents).

The clinical examination was made under standardized lighting conditions by the same examiner, and data were immediately recorded into the special list. Diagnosis was visual, and all teeth and surfaces were examined according to WHO recommendation (11), they noticed every decayed, missing and filled teeth for the calculation of the usual indexes per one child for primary (dmft) and permanent (DMFT) dentition.

The level of the dental care was expressed as the restorative index percentage (ri\%/RI\%), which represents the percentage of decayed teeth that were restored.

Basic anthropometric measures were carried by the same examiner according to standardized routines: height (recorded to the nearest centimetre) and body weight (to the nearest 0.5 $\mathrm{kg}$ ) on lightly dressed children without shoes, and the BMI was calculated depending on age and sex (12).

All data were entered into the MedCalc Software Inc., Belgium, using t-test, Pearson's correlation test (associations of dmft and BMI) and Spearman's correlation test (correlation of dmft/ DMFT); p-value $<0.05$ was considered as statistically significant.

\section{RESULTS}

Caries prevalence and dmft scores were found to be rather high among this age group of children, with no significant differences in relation to gender and/or country; only $30.0 \%$ or less of children were caries free (Table 1). The decayed component formed the

Table 1. Prevalence of caries in primary teeth in relation to gender and country $(N=190)$

\begin{tabular}{|c|c|c|c|c|c|c|c|c|}
\hline \multirow{2}{*}{ Group } & \multirow{2}{*}{$\begin{array}{c}\text { Children } \\
n\end{array}$} & \multicolumn{2}{|c|}{ Caries free } & \multicolumn{2}{|c|}{ With caries } & \multicolumn{2}{|c|}{$\mathrm{dmft}$} & \multirow{2}{*}{ ri\% } \\
\hline & & $\mathrm{n}$ & $\%$ & $n$ & $\%$ & Mean & SD & \\
\hline Male CR & 61 & 19 & 31.1 & 42 & 68.9 & 2.61 & 4.22 & 41.75 \\
\hline Male YE & 50 & 16 & 32.0 & 34 & 40.7 & 2.12 & 3.74 & 0.00 \\
\hline Female CR & 39 & 11 & 28.2 & 28 & 71.8 & 4.31 & 5.96 & 38.17 \\
\hline Female YE & 40 & 10 & 25.0 & 30 & 75.0 & 3.20 & 4.06 & 0.00 \\
\hline
\end{tabular}

SD - standard deviation, ri\% - restorative index percentage 
major part of dmft scores, and the evaluation of ri\% indicates a high percentage of untreated caries and a high treatment need for these children. Especially in Yemen, children's dental caries is wholly untreated. Also in the Czech Republic, the dental care is rather poor.

In this age category, the first individual permanent teeth, incisors and molars were erupting and affected by caries: there were no significant differences between genders or countries. Values for the restorative index for permanent teeth (RI\%) show insufficient and even deficit dental care. The correlations of dmft/DMFT were positive and significant in all subgroups (Table 2).

According to the anthropometric measurements, girls in CR and YE did not significantly differ, while Czech boys were more robust in weight than those from Yemen; as the body height was similar, the significant differences in the BMI was due to the average body weight (higher levels for Czech boys) (Table 3).

The levels of association(s) between oral health markers ( $\mathrm{dmft} /$ DMFT) and BMI were inconsistent (both positive and negative, but always without statistical significance (Table 4).

\section{DISCUSSION}

Dental caries have different prevalence patterns, not only globally, but also in individual countries and within populations. According to the Global Goals for Oral Health for the 21 st century, at least $80 \%$ of children aged 5-6 years should be free of dental caries, and in 12 years old children the mean DMFT should not be higher than 1.5 (13).

Among countries participating in the WHO Oral Health Surveys (3), the changes in trends have been seen over time. Developed countries initially had high prevalence of dental caries, but then it was followed by a continuous decline in prevalence, consistent with improving oral hygiene and appropriate exposure to fluorides. Nevertheless, a high social disparity has been still seen $(14,15)$.

The major risk factor, the intake of cariogenic sweeteners, have not been researched in our study. However, it can be believed that cariogenic sweeteners intake has been rising both in developed and developing countries for many years, leading to increased dental

Table 2. Caries prevalence in permanent teeth and correlation of dmft/DMFT (Spearman's coefficient rho and 95\% Cl)

\begin{tabular}{|l|c|c|c|c|c|c|c|c|c|}
\hline \multirow{2}{*}{ Group } & \multicolumn{2}{|c|}{ Erupting teeth } & \multicolumn{2}{|c|}{ DMFT } & \multicolumn{2}{c|}{ RI\% } & \multicolumn{2}{c|}{ dmft/DMFT } & \multirow{2}{*}{ p-value } \\
\cline { 2 - 11 } & Mean & SD & Mean & SD & Mean & SD & rho & $95 \%$ Cl & \\
\hline Male CR & 1.11 & 2.10 & 0.07 & 0.36 & 3.57 & 18.56 & 0.362 & $0.121-0.592$ & $<0.001$ \\
\hline Male YE & 1.82 & 3.33 & 0.06 & 0.36 & 0.00 & 0.00 & 0.563 & $0.337-0.727$ & $<0.001$ \\
\hline Female CR & 0.64 & 1.58 & 0.05 & 0.22 & 0.00 & 0.00 & 0.577 & $0.320-0.755$ & $<0.001$ \\
\hline Female YE & 1.25 & 2.22 & 0.05 & 0.22 & 0.00 & 0.00 & 0.474 & $0.191-0.685$ & $<0.001$ \\
\hline
\end{tabular}

$\mathrm{SD}$ - standard deviation, $\mathrm{RI} \%$ - restorative index percentage

Table 3. Anthropometric data - differences by t-test $(N=190)$

\begin{tabular}{|c|c|c|c|c|c|c|c|c|c|}
\hline \multirow{2}{*}{ Group } & \multicolumn{3}{|c|}{ Height $(\mathrm{cm})$} & \multicolumn{3}{|c|}{ Weight (kg) } & \multicolumn{3}{|c|}{$\mathrm{BMI}\left(\mathrm{kg} / \mathrm{m}^{2}\right)$} \\
\hline & Mean & SD & $p$-value & Mean & SD & $\mathrm{p}$-value & Mean & SD & $\mathrm{p}$-value \\
\hline Male CR & 109.36 & 10.80 & \multirow{2}{*}{0.057} & 20.14 & 8.77 & \multirow{2}{*}{0.001} & 17.02 & 1.92 & \multirow{2}{*}{0.19} \\
\hline Male YE & 105.88 & 8.20 & & 16.08 & 2.80 & & 14.39 & 1.92 & \\
\hline Female CR & 104.95 & 10.16 & \multirow{2}{*}{0.598} & 16.97 & 3.06 & \multirow{2}{*}{0.265} & 15.42 & 1.95 & \multirow{2}{*}{0.726} \\
\hline Female YE & 103.75 & 9.86 & & 16.10 & 3.77 & & 15.17 & 3.98 & \\
\hline
\end{tabular}

SD - standard deviation, $\mathrm{BMI}$ - body mass index

Table 4. Associations between dmft/DMFT and BMI (Pearson correlation rho and $95 \% \mathrm{Cl}$ )

\begin{tabular}{|c|c|c|c|c|c|c|}
\hline \multirow{2}{*}{ Group } & \multirow{2}{*}{ Indexes } & \multirow{2}{*}{ rho } & \multirow{2}{*}{$95 \% \mathrm{Cl}$} & \multirow{2}{*}{$p$-value } & \multicolumn{2}{|c|}{ BMI } \\
\hline & & & & & Mean & SD \\
\hline \multirow{2}{*}{ Male CZ } & $\mathrm{dmft}$ & -0.145 & $-0.265-0.238$ & 0.2682 & \multirow{2}{*}{17.02} & \multirow{2}{*}{8.5} \\
\hline & DMFT & 0.168 & $-0.087-0.402$ & 0.1951 & & \\
\hline \multirow{2}{*}{ Male YE } & $\mathrm{dmft}$ & 0.152 & $-0.131-0.412$ & 0.3871 & \multirow{2}{*}{14.34} & \multirow{2}{*}{1.92} \\
\hline & DMFT & 0.033 & $-0.247-0.308$ & 0.8200 & & \\
\hline \multirow{2}{*}{ Female CZ } & $\mathrm{dmft}$ & -0.105 & $-0.407-0.217$ & 0.5247 & \multirow{2}{*}{15.42} & \multirow{2}{*}{1.95} \\
\hline & DMFT & -0.036 & $-0.347-0.282$ & 0.8288 & & \\
\hline \multirow{2}{*}{ Female YE } & $\mathrm{dmft}$ & 0.069 & $-0.247-0.382$ & 0.6233 & \multirow{2}{*}{15.17} & \multirow{2}{*}{3.98} \\
\hline & DMFT & -0.021 & $-0.330-0.292$ & 0.8977 & & \\
\hline
\end{tabular}

SD - standard deviation, BMI - body mass index 
problems. Some studies have discovered the strong associations between unhealthy diet, including sweeteners, and BMI, and recommended to assess the BMI in dental offices (16).

In the Czech Republic, dental care is available free of charge, nevertheless, the level of untreated dental caries is high. It can be related to poor oral hygiene, improper dietary habits, high sugar consumption, continuous advertising of sugar and sweets in the media, and a lack of dental care knowledge among parents for pre-school and younger school children. Other additional factors such as late first dental visits and regular follow-up, or even the inability to find a dentist to register with, can also contribute to these results.

Although politicians in the Czech Republic have formally accepted the WHO recommendations concerning children's oral health, we can see the absence of their realization in the practice. Despite the lack of personal and financial support, the regular screening of oral health among representative samples of the population were done only by Lenčová and Broukal (17). In this study, approximately half of children were caries free, and only $21 \%$ of teeth affected with dental caries were treated. Another Czech study by Bálková included participants from only 10 districts in Bohemia part of the CR (18). Our results are very similar, but the number of caries-free children was even lower. It means that the data on caries patterns, which can help to determine the adequacy of the policy by monitoring of children's oral health and planning of treatment, are not exploited in Czech practice.

The similar unpleasant situation was described in a Polish study, where $85.6 \%$ of children aged 6 years displayed cariesaffected dentition (19).

Similar trends have been seen in developing countries such as Yemen. In the study among children in Sana'a City, the dmft score of 6-8 aged children was 6.68 (SD 3.80), $84 \%$ of them needed the treatment of at least one tooth; females had higher restorative and preventive needs than boys. Only $4 \%$ of subjects were caries free, more among boys. (20). Yemen is not an exception, as also in some other Arabian countries, more than $90 \%$ of 6-year-old children had caries in primary teeth $(21,22)$.

In both countries within our study, the average index dmft was higher among girls, as it was described in many studies all over the world. Maybe this can be due to earlier tooth eruption and longer exposure to the environment. These conditions are usually reversed at 6-7 years of age, perhaps due to improved oral hygiene among girls (23), as it was also confirmed in our study; data is not presented.

Childhood obesity and dental caries have common important risk factors: unhealthy dietary habits (high saturated fats, sweets, soft drinks, insufficient intake of fruit, vegetables and sources of calcium). Thus theoretically, obesity can be associated with dental caries, as both diseases have similar age-related cumulative conditions (12).

In some, but not in all epidemiologic studies, the increased prevalence of dental caries among obese children was described compared to normal weight children. In studies with positive results, the significant associations were evident only in children with permanent dentition and in those from the industrialised countries, but not in newly industrialised or developing countries.

The socioeconomic class was a significant moderator (24). In our study, the associations between BMI and $\mathrm{dmft}$ were not confirmed.
Early prevention of caries during pre-school age is the important key for oral health conditions and patterns for the use of dental services in childhood and adult years. Appropriate exposure to fluorides is the community method for primary prevention of dental caries. Clinical studies did show that fluoride exposure, even when applied topically, can significantly reduce the progress of caries lesions in enamel (25).

In our study, participants from both countries had different exposure levels to fluorides. While in the CR drinking water is not supplemented by fluorides and the natural level is rather low (26), in Yemen, natural sources of drinking water contain levels (usually $2-3.8 \mathrm{mg} / \mathrm{L}$ ) exceeding the WHO limits (up to $1.5 \mathrm{mg} / \mathrm{L}$ ) (27). The high levels of fluoride (even $32 \mathrm{mg} / \mathrm{L}$ ) in drinking water in endemic zones not only caused dental fluorosis, but even skeletal fluorosis (28). Additional fluoride sources may be obtained via diet and by ingestion of toothpastes by young children (29).

Dental fluorosis in the deciduous dentition was generally reported as being less severe than in corresponding permanent dentition. The explanation may be a placental barrier to fluoride, the shorter duration of enamel formation and maturation, or the thinner enamel of deciduous teeth (30). Nevertheless, children with fluorosis were found also in our Yemeni sample.

In Yemen, khat (Catha Edulis Forsk) chewing is a widespread social habit practiced not only by adults, but also by children. Many studies described the lower caries experience among khat chewers; this may be a result of mechanical cleaning and fluoride and tannin present in khat's leaves (31).

All epidemiological studies concerning Yemeni children (including our study) describe high prevalence of children never obtaining any dental services. It indicates that families do not care about treating children's teeth, either due to the lack of money to pay for dentist care, or the lack of public awareness of the importance of oral health, and insufficient health and dental services. One can rather speculate about limited dental care availability of pre-schoolers as a matter of both parents and the current Czech dental care system weaknesses.

Our study has some limitations. The samples of children are not representative, nevertheless, our results are very similar to those obtained from larger studies. Due to screening by one contributor and time limitation, it was not possible to describe family social environment, the nutritional habit and oral hygiene skills of children in detail. Surprisingly, it has been discovered that the main indicators of oral health in this age category are similar for both countries: the newly economically transformed Czech Republic and the developing Yemen.

\section{CONCLUSION}

The high prevalence of poor dental health in these groups of Czech and Yemeni children and very low or even no treatment urge WHO recommendations to be accepted for practice in the national health policies.

Prevention and control of dental caries can be promoted by dentists by educating the whole family about dental care and lifestyle.

Reduction of high caries levels can only be changed by the oral hygiene promoting programmes, wide dental health education with the collaboration of schools, paediatricians, general 
practitioners and gynaecologists targeting new and expectant mothers to increase their knowledge and skills.

\section{Conflicts of Interests}

None declared

\section{REFERENCES}

1. Selwitz RH, Ismail AI, Pitts NB. Dental caries. Lancet. 2007;369(9555):519.

2. Seow WK. Biological mechanisms in early childhood caries. Community Dent Oral Epidemiol. 1998;26 Suppl 1:8-27.

3. World Health Organization. Research and action for the promotion of oral health within primary health care: Report on Consultations. Geneva: WHO; 1989.

4. Mattila ML, Rautava P, Ojanlatva A, Paunio P, Hyssala L, Helenius H, et al. Will the role of family influence dental caries among seven-year-old children? Acta Odontol Scand. 2005;63(2):73-84

5. Harris R, Nicoll AD, Adair PM, Pine CM. Risk factors for dental caries in young children: a systematic review of the literature. Community Dental Health. 2004;21 Suppl 1:71-85

6. Gustafsson BE, Quensel CE, Lanke LS, Lundqvist C, Grahnen H, Bonow BE, et al. The Vipeholm Dental Caries Study: the effect of different levels of carbohydrates intake on caries activity in 436 individuals observed for five years. Acta Odont Scand. 1954;11(3-4):232-64.

7. Krasse B. The Vipeholm Dental Caries Study: recollections and reflections 50 years later. J Dent Res. 2001;80(90):1785-8.

8. Burt BA, Pai S. Sugar consumption and caries risk: a systematic review. J Dent Educ. 2001;65(10):1017-23.

9. Mattila ML, Rautava P, Sillanpää M, Paunio P. Caries in five-yearold children and associations with family-related factors. J Dent Res. 2000;79(3):875-81.

10. Tannure PN, Kůchler EC, Lips A, Costa Mde C, Luiz RR, Granjeiro JM, et al. Genetic variation in MMP20 contributes to higher caries experience. J Dent. 2012;40(5):381-6.

11. World Health Organization. Oral health surveys: basic methods. 4th ed. Geneva: WHO; 1997.

12. Hong L, Ahmed A, McCunniff M, Overman P, Mathew M. Obesity and dental caries in children aged 2-6 years in the United States: Nationa Health and Nutrition Examination Survey 1999-2002. J Public Health Dent. 2008;68(4):227-33

13. World Health Organization. Prevention methods and programs for oral diseases. World Health Organ Tech Rep Ser. 1984;(713):1-46.

14. National Institute of Dental and Craniofacial Research. Oral Health in America: a report of the Surgeon General. Rockville: US Department of Health and Human Services; 2000.
15. Petersen PE. The World Oral Health Report 2003: continuous improvement of oral health in the 21 st century - the approach of the WHO Global Oral Health Programme. Community Dent Oral Epidemiol. 2003 Dec;31 Suppl 1:3-23.

16. Curzon ME, Hefferren JJ. Modern methods for assessing the cariogenic and erosive potential of foods. Br Dent J. 2001;191(1):41-6.

17. Lenčová E, Broukal Z. Caries experience in Czech pre-school children Ces Stomatol. 2012;112(6):168-72. (In Czech.)

18. Bálková $\breve{S}$. The monitoring of oral health among children in Czech Republic. Praha: IPVZ; 2010. (In Czech.)

19. Struzycka I, Wierzbicka M, Jodkowska E, Rusyan E, Ganowicz E, Fidecki M. Oral health and prophylactic-therapeutic needs of children aged 6 years in Poland in 2012. Przegl Epidemiol. 2014;68(1):53-7.

20. Al Haddad KA, Al Hebshi NN, Al Ak'hali MS. Oral Health status and treatment needs among school children in Sana'a City, Yemen. Int J Dent Hyg. 2010;8(2):80-5.

21. Stewart BL, Juhani TS, Al Akeel AS, et al. Caries experience in grades 1 and 6 children attending elementary schools in King Abdul-Aziz Military City, Tabuk, Saudi Arabia. Saudi Dent J. 2000;12:140-8.

22. Khan SQ. Dental caries in Arab League countries: a systematic review and meta-analysis. Int Dent J. 2014;64(4):173-80.

23. Lukacs JR, Largaespada LL. Explaining sex differences in dental caries prevalence: saliva, hormones, and "life history" etiologies. Am J Hum Biol. 2006;18(4):540-55.

24. Hayden C, Bowler JO, Chambers S, Freeman R, Humphris G, Richards $\mathrm{D}$, et al. Obesity and dental caries in children: a systematic review and meta-analysis. Community Dent Oral Epidemiol. 2013;41(4):289-308.

25. Browne D, Whelton H, O'Mullane D. Fluoride metabolism and fluorosis. J Dent. 2005;33(3):177-86

26. National Institute of Public Health. Monitoring of drinking water [Internet]. Prague: NIPH [cited 2018 Aug 28]. Available from: http://www. szu.cz/tema/zivotni-prostredi/monitoring-pitne-vody. (In Czech.)

27. Misconi H, Navi M. Medical geology in the Middle East. In: Selinus O, Finkelman RB, Centeno JA, editors. Medical geology: a regional synthesis. Dordrecht: Springer; 2010. p. 135-74.

28. Ozsvath D. Fluoride and environmental health: a review. Rev Environ Sci Biotechnol. 2009;8(1):59-9.

29. Heifetz SB, Horowitz HS. The amount of fluoride in current fluoride therapies: safety consideration for children. ASDC J Dent Child. 1984;51(4):257-69.

30. Levy SM, Hillis SL, Warren JJ, Broffitt BA, Mahbubul Islam AK, Wefe JS, et al. Primary tooth fluorosis and fluoride intake during the first year of life. Community Dent Oral Epidemiol. 2002;30(4):286-95.

31. Hattat FN, Al-Abdulla N. Effect of khat chewing on general and oral health. Dental News. 2001;8(11):33-5 